\title{
BMJ Open Two-year follow-up cohort study focused on gender-specific associations between socioeconomic status and body weight changes in overweight and obese middle-aged and older adults
}

\author{
Malgorzata Biskup, ${ }^{1,2}$ Pawel Macek, ${ }^{1,3}$ Stanislaw Gozdz,, \\ Malgorzata Terek-Derszniak, ${ }^{2}$ Halina Krol, ${ }^{1,5}$ Piotr Kedzierawski, ${ }^{1,6}$ Marek Zak (D) ${ }^{1}$
}

To cite: Biskup M, Macek P, Gozdz S, et al. Two-year followup cohort study focused on gender-specific associations between socioeconomic status and body weight changes in overweight and obese middle-aged and older adults. BMJ Open 2021;11:e050127. doi:10.1136/ bmjopen-2021-050127

- Prepublication history and additional supplemental material for this paper are available online. To view these files, please visit the journal online (http://dx.doi.org/10.1136/ bmjopen-2021-050127)

Received 21 June 2021 Accepted 05 July 2021

D Check for updates

(C) Author(s) (or their employer(s)) 2021. Re-use permitted under CC BY-NC. No commercial re-use. See rights and permissions. Published by BMJ.

For numbered affiliations see end of article.

Correspondence to

Dr Marek Zak; mzak1@onet.eu

\section{ABSTRACT}

Objective As overall spread of obesity in populations is generally acknowledged to result from unhealthy lifestyles rather than individual genetic makeup, this study aimed to gain specific insights into its determinants through assessing the prevalent associations between individual socioeconomic status (SES) and weight loss in overweight and obese men and women.

Methods A prospective, 2-year follow-up study covered 3362 (38.0\% men) respondents, aged 43-64 years, body mass index $\geq 25 \mathrm{~kg} / \mathrm{m}^{2}$. Changes in body weight were estimated as a percentage of initial weight. Three categories of changes were defined: gained $\geq 3 \%$, stable (gained $<3 \%$ or lost $<3 \%$ ), lost $\geq 3 \%$. Body weight loss was determined against three categories: lost $\geq 3$ to $<5 \%$, lost $\geq 5$ to $<10 \%$, lost $\geq 10 \%$. Select SES variables (ie, gender, age, education, marital status, occupational activity and income) were determined in line with the Health Status Questionnaire. The associations between SES and body weight changes were analysed with the aid of logistic regression models. The results were presented as ORs with $95 \% \mathrm{Cls}$.

Results Only $18 \%$ of the respondents had complied with the medical recommendations on weight loss. Significant differences were encountered between the gender, age and occupational activity variables and the weight loss one. Multifactorial models were used to determine the following gender-specific associations between SES and weight loss. Men with moderate income had significantly higher odds for weight loss ( $\approx 75 \%$ ), as compared with the higher earners, whereas women with low income, occupationally inactive, had significantly higher odds $(\approx 30 \%$ and $\approx 50 \%$, respectively), as compared with the high earners and occupationally active ones.

Conclusions Lower education, male gender, lower income per household, older age and unemployment status were the established factors predisposing to obesity. While aiming to ensure effectiveness of the measures specifically aimed at preventing obesity, population groups deemed most at risk of potential weight gain must prior be identified.

\section{INTRODUCTION}

Overweight and obesity are generally acknowledged a global health issue, primarily in view
Strengths and limitations of this study

- Prospective character of the study, pursued on a large group of respondents.

- Effective identification of the population groups particularly at risk of obesity through anthropometric measurements and individual socioeconomic status data.

- Specific insights gained into the factors determining pursuit of detrimental lifestyle paradigms by the at-risk population groups may potentially aid development of more effective public health policies on preventing obesity.

- The focus set exclusively on the assessment of individual weight changes did not facilitate assessment of any modifications in attendant lifestyle paradigms.

- No specifically designed, lifestyle-related weight loss plan proved a significant limitation of the study.

of its magnitude. Not only does its overall complexity entail a number of key medical aspects, but also reflects social, economic and cultural changes. As evidenced by epidemiological data, overweight and obesity relate to both sexes, all races and age groups, in both the highly developed and economically lowincome and middle-income countries. ${ }^{1-3}$

The associations between obesity and increased morbidity and mortality are corroborated by numerous studies. It is widely acknowledged that this condition is associated with many disorders, including glucose intolerance, insulin resistance, hyperinsulinemia, hypertension and dyslipidaemia. ${ }^{4-9}$ This in turn translates into increased public healthcare expenditure. ${ }^{4-7}$

Incidence of overweight and obesity is promoted by specific factors appreciably reducing individual energy expenditure (ie, reduced physical activity), and those which 
cause increased energy intake. ${ }^{8}{ }^{9}$ According to WHO, in 2016 alone, the problem of overweight and obesity affected 1.9 billion people worldwide, of whom more than 650 million were affected by obesity. ${ }^{10}$ Owing to complications related to overweight and obesity, estimated 2.8 million people die annually, whereas prevalence of obesity still remains on the rise. ${ }^{10}$

Before 1990s, the aetiological studies of obesity focused mainly on biological explanations, very few of them actually dedicated to exploring social and psychological causes. Ever since Sobal and Stunkard's far-reaching review, ${ }^{11}$ the relationship between socioeconomic status (SES) and obesity had quickly become the hot spot of research. ${ }^{2}$ The existing trend in overall spread of obesity is attributed primarily to unhealthy lifestyles rather than individual genetic makeup. ${ }^{512}$

When setting out to address the issue of obesity, it is hard to ignore overall health benefits which weight loss may bring about. Securing this objective should invariably be linked to implementing a radical change in an individual lifestyle, a personalised (individually designed) dietary intake, and appreciably increased physical activity. Any pragmatically structured exercise programmes should take into account the key factors, i.e. frequency, intensity and duration. Every individually pursued weight loss process should always be implemented under expert guidance of a dietician. ${ }^{13}$

Substantial rise in the prevalence of obesity worldwide has apparently eluded attention of the health professionals specifically tasked with regular monitoring of key population health indicators, up to the point whereupon the problem we are now faced with may well be dubbed a true scourge of the 21st century. It seems only prudent therefore to strive to gain some insights into the specific social and economic factors which underpin overall complexity of this widely acknowledged health hazard.

As overall spread of obesity in populations is generally acknowledged to result from unhealthy lifestyles rather than individual genetic makeup, this study aimed to gain specific insights into its determinants through assessing the prevalent associations between individual SES and weight loss in overweight and obese men and women.

\section{METHODS}

\section{Patients and methods}

The Polish-Norwegian Study and the Healthy Kielce Project

The Polish-Norwegian Study (PONS), conducted in 2010-2011, was a continuation of the International Health Monitoring-Closing the Gap Project, carried out in the Oncology Centre in Warsaw. The Project aimed to assess the key determinants of individual health, as well as gain much deeper insights into the actual causes of morbidity and mortality in Poland. The study's location was selected in due consideration of commonly acknowledged risk paradigms for major non-communicable diseases, exposure to environmental risk factors, level of regional economic development, existing infrastructure and overall commitment to the Project's objectives.

Permanent residents were recruited for the study from a single urban district (of the city of Kielce), that is, 60 000 residents, aged $45-64$ years, out of which $13 \%$ were covered by the PONS population sample, and from a single rural district (Kielce district), that is, 50000 residents, aged 45-64 years, out of which $10 \%$ were covered by the PONS population sample.

The study protocol comprised the following components: Health Status Questionnaire, medical examinations, anthropometric measurements (body weight, height, waist circumference, hip circumference) and collection of biological material (urine and blood samples). The survey questionnaire covered the following sections: health status (general health status, disease history), demographic and social factors (gender, age, education, marital status, professional work, type of occupation, total monthly net income of all household members), mental health and lifestyle (smoking, alcohol consumption, diet, physical activity). Information on gender, education, marital status, professional work and total monthly net income of all household members was collected through a direct interview.

Consequently, within 16 months, 12\% ( $\mathrm{n}=13$ 172) of the target population was recruited for the PONS survey, including 4799 residents of Kielce. After 2 years, in all participants in the PONS survey (pursued within the framework of the Healthy Kielce (HK) Survey Project) who were also permanent residents of Kielce $(n=4799)$ individual health status was reassessed, making use of the same baseline (PONS) methodology as upon the commencement of the study. ${ }^{613-16}$

\section{Data verification}

The data of PONS respondents, collected in 2010-2011, regarding permanent residents of the city of Kielce only $(n=4799)$, were subjected to stringent verification. Data of all respondents $(\mathrm{n}=1321)$ characterised by body mass index (BMI) $<25 \mathrm{~kg} / \mathrm{m}^{2}$ were excluded from the analyses. In this group, 18 cases with $\mathrm{BMI}<18 \mathrm{~kg} / \mathrm{m}^{2}$ (underweight) were reported. Then 116 cases of missing SES data were excluded from the analyses. Verification of the follow-up data did not reveal any missing data in the results variables under study. Ultimately, 3362 (38.0 men) cases were pronounced fully eligible for assessment within the scope of the study protocol (figure 1).

\section{Anthropometric measurements}

On both the first and second assessment, the same measuring tools were used. The body weight was measured with an accuracy of $0.1 \mathrm{~kg}$ using the Tanita S.C.-240 MA body composition analyser. Body height, in an upright position and waist circumference were measured with Seca height measure and a metric tape to an accuracy of $0.1 \mathrm{~cm}$, respectively. BMI was calculated as the quotient of body mass in kilograms and square body height in metres 


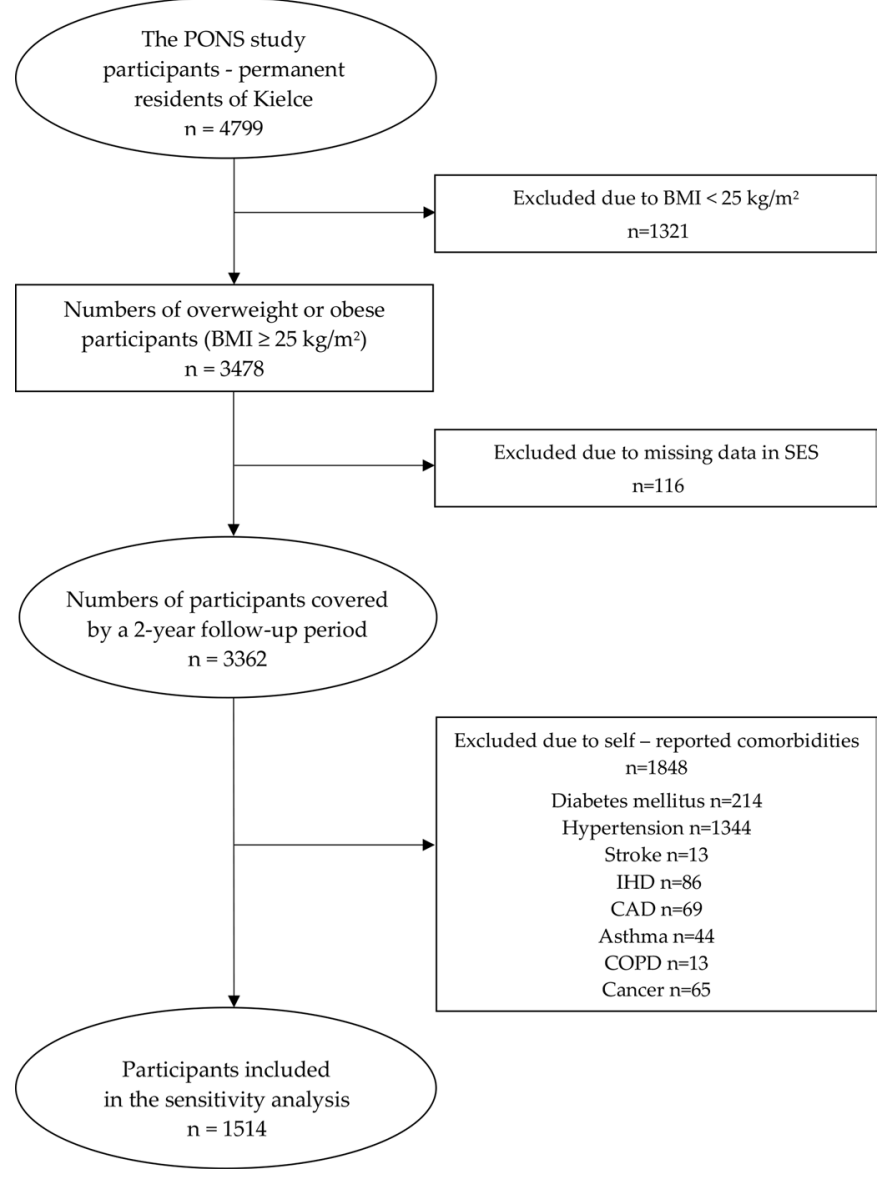

Figure 1 Flow diagram of the selection process in the main and the sensitivity analyses. BMI, body mass index; CAD, coronary artery disease; COPD, chronic obstructive pulmonary disease; IHD, ischaemic heart disease; PONS, Polish-Norwegian Study; SES, socioeconomic status.

$\left(\mathrm{kg} / \mathrm{m}^{2}\right)$. Overweight and obesity were defined by BMI values $\geq 25 \mathrm{~kg} / \mathrm{m}^{2}$ and $\geq 30 \mathrm{~kg} / \mathrm{m}^{2}$, respectively.

The respondents of the PONS study were given recommendations implied by the results of general fat cover assessment, including fat reduction, maintenance or increase of body weight, in conjunction with the guidelines on dietary intake and physical activity. In order to assess the changes in the variables under study in the HK Project, the respondents were addressing the questions referring to compliance with the previously given recommendations.

\section{Individual SES}

Individual SES was established against the Health Status Questionnaire. When carrying out a direct survey, specifically trained Project personnel collected pertinent data on the participants' gender, age, education, marital status, activity, net income per household and any comorbidities.

\section{Patient and public involvement}

The authors represent that neither any patients, nor any members of the public were in any way involved in designing, nor in conducting the study protocol. In view of the actual specifics of its design, the Authors do not envisage having the study outcomes disseminated to its participants.

\section{Statistical analyses}

The weight change in kilograms was calculated as a percentage change in the HK study compared with PONS (baseline). For the purpose of characterisation, the following three categories of body weight changes were defined, that is, gained $\geq 3 \%$, stable (gained $<3 \%$ or lost $<3 \%$ ), lost $\geq 3 \%$. For assessing the amount of weight loss in the SES categories under study, three categories of weight loss were applied, that is, lost $\geq 3$ to $<5 \%$, lost $\geq 5$ to $<10 \%$, lost $\geq 10 \%$. The basic statistics are presented as mean \pm SD, or absolute number and proportion. The distribution of body weight changes in respective SES categories was determined using a $\chi^{2}$ test. The significance of weight loss differences in respective SES categories was assessed by t-test (equal variance), Welch test (unequal variance) or Kruskal-Wallis one-way analysis of variance by ranks, with pairwise comparison test with Benjamini and Hochberg adjustment method. Equal variance was tested by Lovene's test. The associations of weight changes with respective SES categories were assessed with the aid of logistic regression models, and presented as the ORs and 95\% CI. The CIs were based on a profiled reliability logarithm function. Values of $P<0.05$ were considered statistically significant. All analyses were conducted in R V.3.5.3.

\section{Sensitivity analysis}

A sensitivity analysis was carried out for associations between SES and body weight changes. All cases $(n=1.848)$ acknowledging self-reported comorbidities were deleted from the study database. Then, much as in the main analysis, the associations under study were assessed with the aid of logistic regression models (figure 1).

\section{RESULTS}

The study involved 3362 (38.0\% men), participants of PONS and HK research projects, aged 43-64 years (mean age 55.7 years). Both average body weight $(80.6 \mathrm{~kg})$ and BMI $\left(29.6 \mathrm{~kg} / \mathrm{m}^{2}\right)$ differed significantly in the designated categories of body weight changes. With the exception of education, marital status and net income per household, significant differences were found between respective categories of select socioeconomic factors under study (table 1).

Based on BMI value, obesity at baseline was more prevalent in men than in women, in older persons compared with the younger aged ones, respondents with lower levels of education and those occupationally inactive (figure 2). Obesity was also associated with the net income per household. Individuals from the lower-income families were more likely to be obese, as compared with those boasting higher income. This linkage was no longer so manifest in the persons who had left their income undisclosed. It cannot be ruled out that this particular category $(\approx 40 \%$ of all respondents) may also have covered some individuals 
Table 1 Basic characteristics of the study group at baseline, total and stratified by the select weight change categories

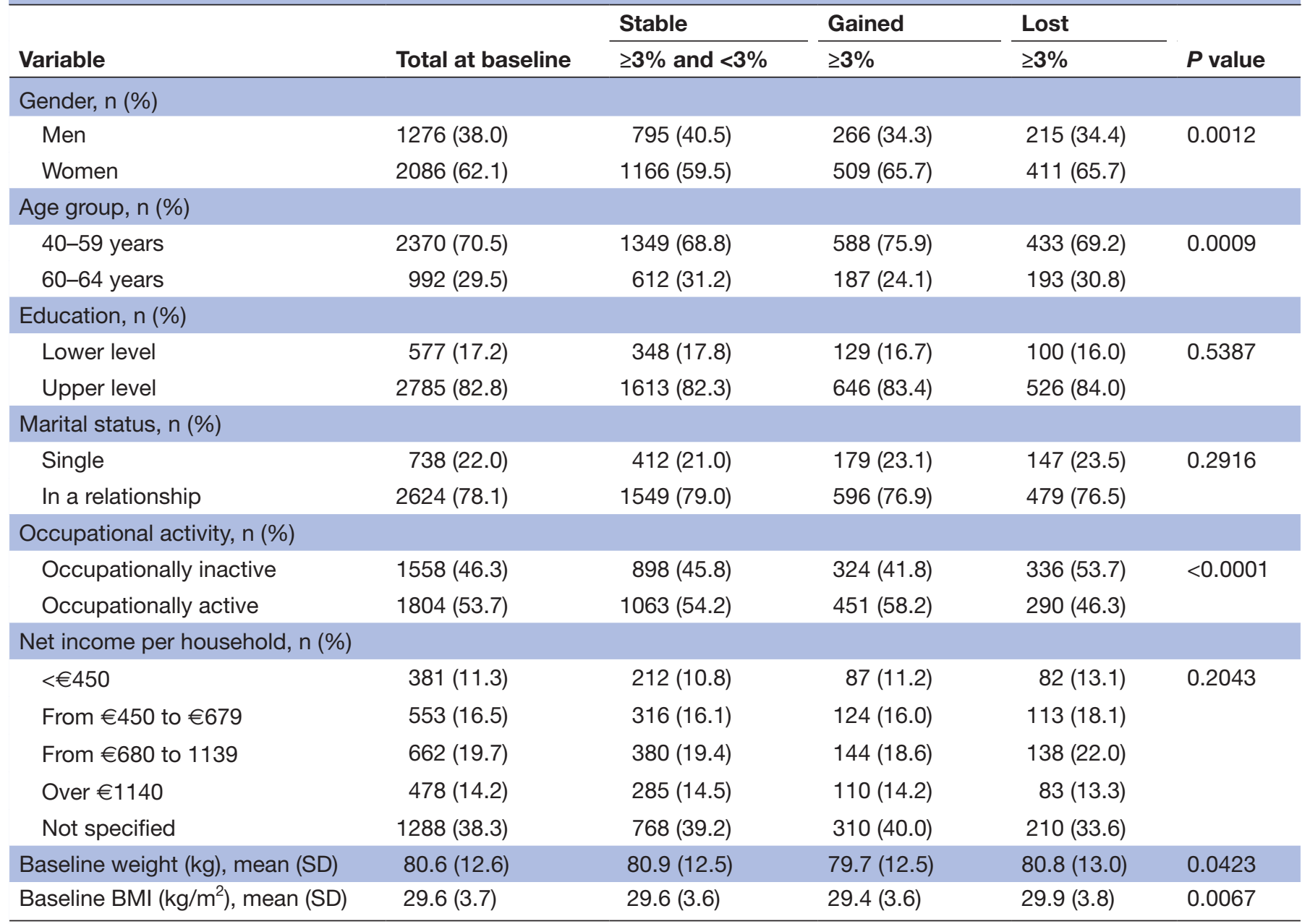

$P$ is statistically significant at alpha level of 0.05 .

BMI, body mass index.

already allocated to all previously designated categories of net income per household.

In the present study, weight loss applied to $\approx 18 \%$ of respondents only. It was noted, however, that regardless of a specific socioeconomic factor, individual weight loss paradigm in respective categories was very similar (table 2). In the $3 \%-5 \%$ and $5 \%-10 \%$ categories, significantly higher weight loss values were observed in men, as compared with women. Also in the $5 \%-10 \%$ category, significantly higher values of weight loss were observed in the individuals with lower education, as compared with their high educated counterparts. In the 5\%-10\% weight loss category, the individuals boasting net income over $€ 1.140$ per household differed significantly in the amount of weight loss from those falling within the following categories: $<€ 450, € 680-1.139$ and of unspecified income.

Based on the regression models, it was established that female gender was associated with body weight changes $>3 \%$ (loss or gain), whereas the male gender was associated with maintaining stable body weight (table 3). In women, older age was significantly associated with maintaining stable body weight, and a lesser risk of weight gain. Women's occupational activity reduced their chances of weight loss by $\approx 35 \%$. Net income per household reduced women's chances of losing weight, whereas the women boasting the highest net income had $\approx 60 \%$ higher chances of gaining weight, as compared with the ones on the lowest income $(<€ 450)$. In men, unlike in women, higher net income per household significantly increased the chances of weight loss, while being at the same time associated with diminished chances of weight gain by $\approx 50 \%$. After excluding from the study database all cases acknowledging self-reported comorbidities, the ORs values continued to indicate the existence of the associations under study, even though their relevance was less manifest. In view of very broad $95 \%$ CIs, assessment of the association between SES and net income per household in men proved diagnostically pointless (online supplemental table S1).

Multifactorial regression models were used to establish the gender-dependent coincidence of socioeconomic weight loss determinants (table 4). In men, the association between socioeconomic factors and weight loss was 


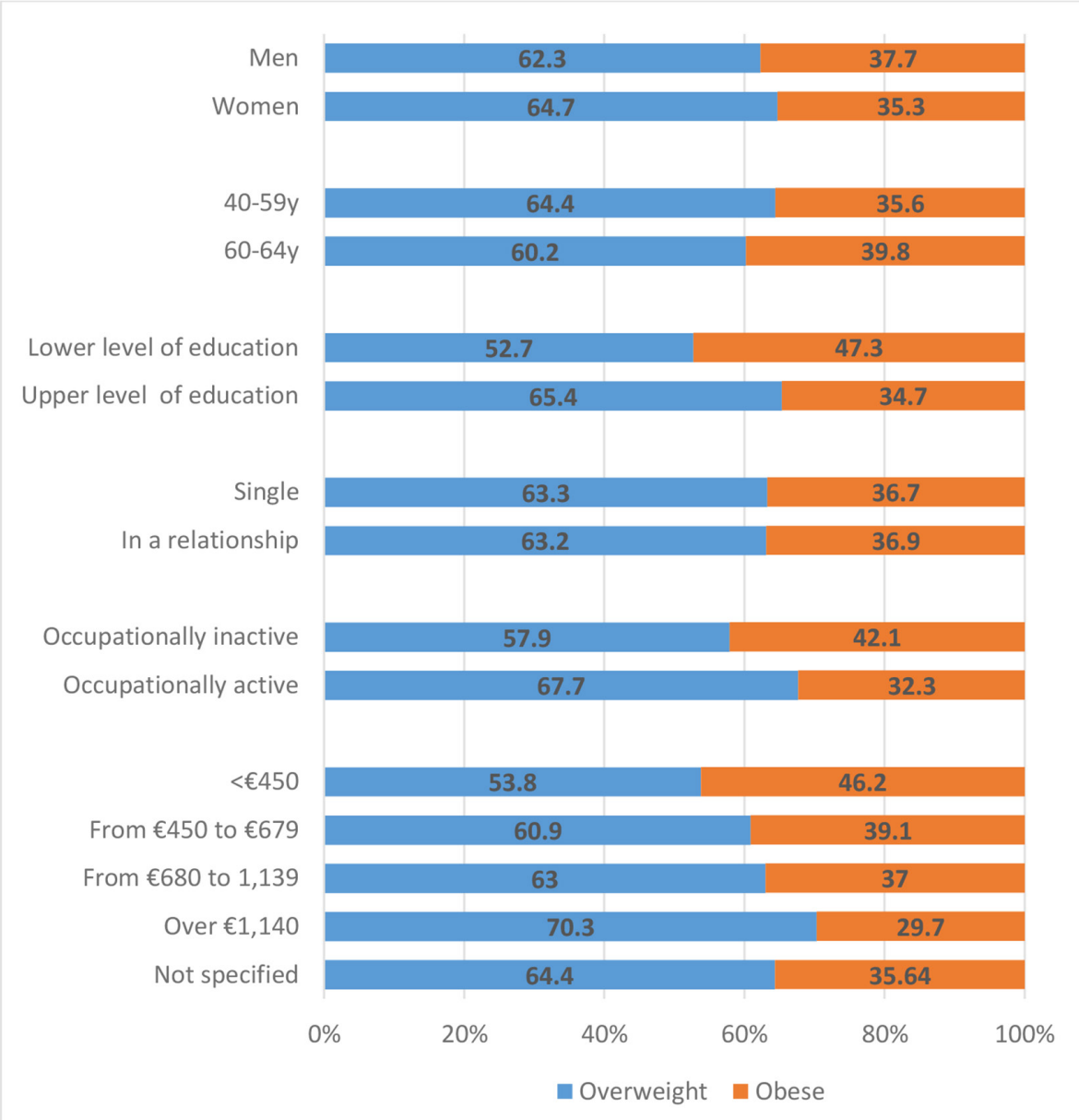

Figure 2 Distribution of overweight and obese classification, based on BMI, stratified by the select categories of socioeconomic factors. BMI, body mass index.

best described by a four-factor model, taking into account younger age, staying in a relationship, occupational inactivity and moderate income, that is, the only factor contributing significant input to the model algorithm. In women, a three-factor model was selected to address this association, as it took into account higher education, occupational inactivity and the lowest income levels. A significant input into this model was noted only in the case of occupational inactivity.

\section{DISCUSSION}

The present study aimed to assess the association between SES and the proportion of body weight loos in overweight and obese individuals. At baseline, obesity was more prevalent in men, elderly persons with lower level of education, occupationally inactive and the ones on lower incomes. After 2 years, a reassessment of body weight indicated that only $18 \%$ of the respondents had followed specific recommendations to ensure weight loss. Weight loss was more frequent in women, younger persons, those boasting higher education, occupationally inactive and those in a relationship. The applied multifactorial models helped establish the gender-specific paradigm between individual weight loss and SES. In men, the chance of weight loss was insignificantly higher in the younger age groups $(\approx 18 \%)$, without a partner $(\approx 40 \%)$ and occupationally inactive $(\approx 20 \%)$ and significantly higher $(\approx 75 \%)$ in men with moderate income. In women, the chance of losing body weight was significantly higher $(\approx 50 \%)$ with regard to occupational inactivity, and insignificantly $(\approx 40 \%)$ in women boasting higher education, and $(\approx 30 \%)$ in those on the lowest income.

The more frequent weight loss, as observed in women, may well be attributable to the blurring of the differences in behavioural patterns in both genders, steadily growing popularity of fitness clubs, and widespread promotion of a 'perfect' figure in the media, a concept women are known to be appreciably more conducive to. ${ }^{17-19}$ Needless to say, individual decisions on weight loss are not always dictated by health considerations, whereas for women, it is mainly the aesthetic or social considerations that appear to hold far more appeal. ${ }^{5}$ In the study of Assari $e t$ $a l l^{5}$ women were found to be far more likely to perceive themselves as overweight, and more frequently advertised their intention to lose weight. Their greater motivation to lose weight was likely due to higher social pressure to look slim, as well as general concerns about their appearance at large. 
Table 2 Loss in body weight, spanning baseline and a 2-year follow-up period, stratified by the select socioeconomic factors

\begin{tabular}{|c|c|c|c|c|}
\hline & Baseline & Lost & Lost & Lost \\
\hline Variable & Weight & $\geq 3 \%$ and $<5 \%$ & $\geq 5 \%$ and $<10 \%$ & $\geq 10 \%$ \\
\hline \multicolumn{5}{|l|}{ Gender } \\
\hline Men & $89.5 \pm 12.0$ & $-3.3 \pm 0.6^{\star \star \star}$ & $-6.1 \pm 1.7^{\star \star \star}$ & $-12.7 \pm 5.3$ \\
\hline Women & $76.2 \pm 11.0$ & $-2.9 \pm 0.6$ & $-5.2 \pm 1.3$ & $-10.8 \pm 3.2$ \\
\hline \multicolumn{5}{|l|}{ Age group } \\
\hline $40-59$ years & $81.2 \pm 12.8$ & $-3.1 \pm 0.6$ & $-5.6 \pm 1.5$ & $-11.3 \pm 3.9$ \\
\hline $60-64$ years & $79.8 \pm 13.3$ & $-3.1 \pm 0.6$ & $-5.3 \pm 1.6$ & $-10.6 \pm 3.2$ \\
\hline \multicolumn{5}{|l|}{ Education } \\
\hline Lower level & $84.3 \pm 13.7$ & $-3.1 \pm 0.7$ & $-6.1 \pm 1.8^{*}$ & $-11.6 \pm 2.3$ \\
\hline Upper level & $80.1 \pm 12.7$ & $-3.0 \pm 0.6$ & $-5.4 \pm 1.5$ & $-11.1 \pm 3.8$ \\
\hline \multicolumn{5}{|l|}{ Marital status } \\
\hline Single & $77.2 \pm 13.5$ & $-3.0 \pm 0.7$ & $-5.3 \pm 1.4$ & $-10.6 \pm 2.9$ \\
\hline In a relationship & $81.8 \pm 12.6$ & $-3.1 \pm 0.6$ & $-5.6 \pm 1.6$ & $-11.3 \pm 3.9$ \\
\hline \multicolumn{5}{|l|}{ Occupational activity } \\
\hline Occupationally inactive & $79.8 \pm 12.8$ & $-3.1 \pm 0.6$ & $-5.5 \pm 1.6$ & $-11.1 \pm 4.2$ \\
\hline Occupationally active & $81.8 \pm 13.1$ & $-3.1 \pm 0.6$ & $-5.5 \pm 1.5$ & $-11.3 \pm 2.5$ \\
\hline \multicolumn{5}{|l|}{ Net income per household } \\
\hline$<€ 450$ & $78.8 \pm 13.2$ & $-3.1 \pm 0.7$ & $-5.3 \pm 1.4^{*}$ & $-9.4 \pm 2.1$ \\
\hline From $€ 450$ to $€ 679$ & $81.6 \pm 13.9$ & $-3.0 \pm 0.6$ & $-5.9 \pm 2.0$ & $-10.5 \pm 4.1$ \\
\hline From $€ 680$ to 1139 & $79.3 \pm 11.5$ & $-3.0 \pm 0.6$ & $-5.1 \pm 1.3^{\star \star}$ & $-13.4 \pm 4.5$ \\
\hline Over $€ 1140$ & $85.1 \pm 14.6$ & $-3.1 \pm 0.6$ & $-6.3 \pm 1.8^{\text {ref }}$ & $-9.9 \pm 1.0$ \\
\hline Not specified & $80.3 \pm 12.2$ & $-3.1 \pm 0.6$ & $-5.3 \pm 1.3^{* *}$ & $-11.2 \pm 3.5$ \\
\hline
\end{tabular}

Data are presented as mean \pm SD.

${ }^{\star} P<0.05,{ }^{\star \star} P<0.01,{ }^{\star \star *} P<0.001$.

In the present study, weight loss was observed more frequently in the individuals boasting higher level of education. In other studies, higher education was also positively correlated with pursuit of health-promoting lifestyle, good eating habits, and physical activity. ${ }^{20-24}$ This correlation was corroborated by Zhang $e t a l^{25}$ in the study involving 7351 individuals, aged 20-79 years. Higher education was found to reduce the chance of being overweight or obese in women, although not so in men. Also women boasting higher income, as opposed to men, were more likely to have normal body weight. It is generally assumed that individual level of education remains stable throughout one's lifetime, and to a certain extent reflects SES enjoyed back in childhood. ${ }^{26}$

Even though the association between SES and healthpromoting lifestyle may be looked on as a single factor, it is worth noting that SES level is determined by a coincidence of several factors simultaneously. ${ }^{27}$ Individuals boasting higher education are more likely to find a well-paid job, enter into relationships with persons of similar SES, as well as hold health insurance policies affording them effective access to highly specialised medical care ${ }^{28}$ is also worth noting at this juncture the regional socio-cultural inequalities in terms of education and remuneration packages offered to men and women. Women's general determination to achieve and maintain high social status may well be reflected through their desire to maintain a lean body, as well as pursue and promote a healthy lifestyle. ${ }^{29-33}$ The association between income and obesity was also investigated by other authors, in conjunction with the level of economic development of respective countries. ${ }^{20} 3435$

In the developed countries, obesity is widely recognised as a condition that affects people with lower SES, whereas in the developing ones, there is an ongoing debate on whether obesity mainly affects the poor or the $\operatorname{rich}^{28} 3637$ The linkage between obesity and SES is corroborated by the Newton et al study. ${ }^{17}$ Women with higher SES had lower BMI throughout their lives, while the results for men were appreciably less consistent. A potential causative factor for this variation consists in a frequently observed sense of perfect physique and/or body weight in women. While it is easier for women boasting a higher income to achieve and maintain it, it is also highly likely that such a paragon of bodily perfection does not really fall within the scope of men's desire whatsoever. Also in men with low SES, correct body weight may be due to high physical activity associated with higher levels of occupational activity and the actual nature of their jobs. ${ }^{17-19}$ 


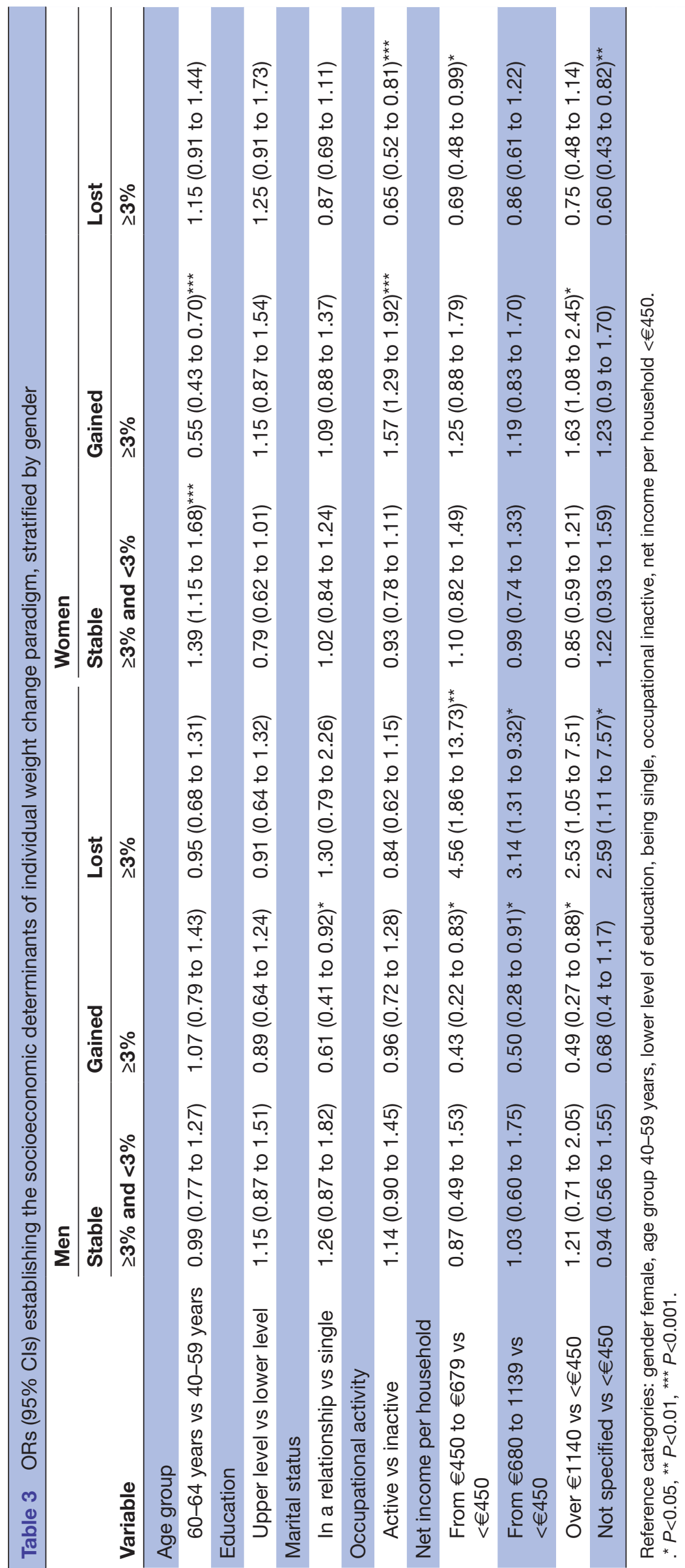


Table 4 Multivariate regression models establishing the socioeconomic determinants of individual weight loss paradigm, stratified by gender

\begin{tabular}{|c|c|c|c|}
\hline Multivariate model & Men & Multivariate model & Women \\
\hline \multicolumn{4}{|l|}{ Five-factor model } \\
\hline Age group+ & & Age group+ & \\
\hline $40-59 y$ vs $60-64$ & 1.17 (0.82 to 1.69$)$ & $60-64$ years vs $40-59$ years & 0.91 (0.71 to 1.18$)$ \\
\hline Education+ & & Education+ & \\
\hline Lower level vs upper level & $1.02(0.70$ to 1.45$)$ & Upper level vs lower level & 1.37 (1.00 to 1.91$)$ \\
\hline Marital status+ & & Marital status+ & \\
\hline In a relationship vs single & 1.39 (0.84 to 2.42$)$ & Single vs in a relationship & $1.06(0.82$ to 1.36$)$ \\
\hline Occupational activity+ & & Occupational activity+ & \\
\hline Inactive vs active & 1.19 (0.85 to 1.67$)$ & Inactive vs active & $1.57(1.22 \text { to } 2.02)^{\star \star \star x}$ \\
\hline Net income per household & & Net income per household & \\
\hline From $€ 450$ to $€ 679$ vs others & $1.75(1.15 \text { to } 2.62)^{\star \star}$ & $<€ 450$ vs others & 1.29 (0.94 to 1.75$)$ \\
\hline
\end{tabular}

Four-factor model

\begin{tabular}{|c|c|c|c|}
\hline \multicolumn{2}{|l|}{ Age group+ } & \multicolumn{2}{|l|}{ Education+ } \\
\hline $40-59$ years vs $60-64$ years & $1.18(0.83$ to 1.69$)$ & Upper level vs lower level & $1.37(1.00$ to 1.91$)$ \\
\hline Marital status+ & & Marital status+ & \\
\hline Occupational activity+ & & Occupational activity+ & \\
\hline Inactive vs active & 1.20 (0.85 to 1.67$)$ & Inactive vs active & $1.51(1.21 \text { to } 1.91)^{\star \star \star}$ \\
\hline From $€ 450$ to $€ 679$ vs others & $1.76(1.16 \text { to } 2.62)^{\star \star}$ & $<€ 450$ vs others & $1.28(0.94$ to 1.75$)$ \\
\hline \multicolumn{4}{|l|}{ Three-factor model } \\
\hline Marital status+ & & Education+ & \\
\hline In a relationship vs single & $1.38(0.84$ to 2.40$)$ & Upper level vs lower level & 1.37 (1.00 to 1.91$)$ \\
\hline From $€ 450$ to $€ 679$ vs others & $1.75(1.15 \text { to } 2.61)^{\star \star}$ & $<€ 450$ vs others & $1.31(0.98$ to 1.75$)$ \\
\hline \multicolumn{4}{|l|}{ Two-factor model } \\
\hline Marital status+ & & Education+ & \\
\hline In a relationship vs single & $1.36(0.83$ to 2.37$)$ & Upper level vs lower level & $1.36(0.99$ to 1.89$)$ \\
\hline Net income per household & & Occupational activity & \\
\hline From $€ 450$ to $€ 679$ vs others & $1.80(1.19 \text { to } 2.66)^{\star \star}$ & Inactive vs active & $1.58(1.26 \text { to } 1.98)^{\star \star \star}$ \\
\hline
\end{tabular}

Data are presented as OR $(95 \% \mathrm{Cl})$. Reference categories: gender female, age group 40-59 years, lower level of education, being single, occupational inactive, net income per household $<€ 450$. Other categories of net income per household are comprised in table 3.

${ }^{\star \star} P<0.01,{ }^{* \star *} P<0.001$.

A smaller obesity problem in women boasting higher SES $^{1738} 39$ may well be attributed to higher availability of a well-balanced diet, healthy foods and their keener interest in pursuit of physical activity. Interesting research results on the relationship between obesity and social factors, pertaining to a group of 10448 same-sex twins aged 18-79 years were reported by Liao et al. ${ }^{1}$ At an individual level, both education and marital status were associated with higher BMI and a higher risk of overweight and obesity in men, while in women, the effect of education level on BMI was exactly the opposite. Married twins had a much higher BMI, as compared with the unmarried twins, except for older women.

The higher level of education was associated with higher BMI in both older women and men. Similarly, Soriguer $e t$ $a l^{40}$ reported a higher prevalence of obesity in married couples up to the age of 45 years, whereas the divorced persons over that age manifested the highest prevalence of obesity. The study by Kilicarslan et a $t^{41}$ established a higher prevalence of obesity in married persons, as compared with single or divorced/divorced persons. The authors subscribed to the view that marriage increased 
the risk of obesity by 2.5 times. The precise mechanism linking obesity and marriage is not fully understood.

According to Tzotzas et al, ${ }^{42}$ there are two most credible hypotheses explaining an increase in BMI during marriage. The authors highlight the social obligation of marriage, whereby married couples tend to eat more regular meals and more calorific foods, and the marriage market hypothesis, whereby married couples, especially women, being no longer on the lookout for a potential life companion (partner), consequently lose their natural motivation to keep a slim figure. The third hypothesis is also being considered, that is, the selection hypothesis, which tentatively assumes that individuals with a lower BMI are more likely to find a partner and get married, which, according to the investigators, may be particularly appealing to women.

\section{Strengths and limitations}

The present study suffers from certain limitations, though, which need to be addressed here. The source data sets originating from both PONS and the HK studies may not reflect the current SES of the population from which the study cohort was actually drawn. A decade has lapsed since the completion of both research projects, bearing witness to a number of socioeconomic changes taking place in Poland, primarily a rising affluence of the population at large, accompanied by an appreciable increase in the number of individuals having acquired a higher level of education. This notwithstanding, the Authors would like to highlight that their primary objective was focused on assessing the association of SES with weight loss, based on the study cohort, and not for the study cohort under study.

In those terms the study seems to be still current, as within any population there are disparities in SES reflecting the differences in individual health behaviour, as defined by the SES-health gradient. Disparities between respective SES groups generally remain on the rise until the end of the fourth decade of individual's life, subsequently either stabilising or decreasing. This paradigm is observed across different countries, regardless of economic, healthcare or welfare systems in place. It is most likely that rational, age-related health behaviour, in conjunction with relative consistency of SES may be appreciably instrumental in this.

It should also be emphasised at this juncture that assessment of the association of SES with weight loss, as based on the PONS-HK project has never been probed prior to the present investigative effort. Even though selfmonitoring of body weight is a commonly used method in weight management interventions, it would appear that individuals frequently fail to implement their own action plans, or adopt a rather unrealistic approach in mapping them out in the first place. It is therefore expedient to have some additional components of weight loss treatment incorporated, with a view to enhancing overall effectiveness of its management.
As already referenced further above, body weight loss only affected $\approx 18 \%$ of the study respondents. The desirable health-promoting behaviour pursued by such a low percentage of respondents was probably prompted by a one-off, specific medical recommendation to lose weight, although unaccompanied by any tangible support across a 2-year follow-up period. Besides, no periodic weight measurements were carried out either, which effectively made it non-feasible to distinguish between maximum weight loss and its regaining following previous loss.

Quite likely, unsuccessful and therefore frustrating weight loss attempts may have been made by a much larger number of respondents, although owing to lack of any tangible support measures some of those attempts may well have been discontinued. Overall frustration experienced at the lack of the anticipated outcomes may well have prompted some of the respondents to discontinue their efforts. Self-monitoring of body weight is a minimal strategy which relies primarily on the actual outcome assessment rather than on individual health behaviour. In order to have overall effectiveness of weight loss treatment enhanced, it is necessary to change individual behavioural paradigm, mainly in terms of modifications introduced into individual dietary intake, along with boosting one's physical activity level. The fact that the present study did not comprise a behaviourally related weight loss component may indeed have been one of its limitations.

Admittedly, the actual strength of the presented study consists in its prospective character, a large group of respondents, in which both the direct anthropometric measurements and data regarding individual SES were collected by the trained project staff making use of adequately selected research tools.

\section{CONCLUSIONS}

Lower education, male gender, lower income per household, older age and unemployment status were established as the factors predisposing to obesity.

Higher weight loss (in the $3 \%-5 \%$ and $5 \%-10 \%$ categories) was more frequently observed among men. Also in the $5 \%-10 \%$ category, significantly higher values of weight loss were observed in the individuals with lower education, as compared with the ones boasting a higher one.

As only $18 \%$ of the study subjects complied with specific medical recommendations on body weight loss, a comprehensively structured remedial action is required, for example, by way of introducing a target-oriented, educational support scheme, designed and structured to effectively address the psychological, dietary and physical activity aspects of any such individually pursued weight loss effort.

In order to ensure overall effectiveness of the measures specifically aimed at preventing obesity, population groups deemed most at risk of potential weight gain must prior be identified, to which the findings of the present study are believed to specifically contribute. 
Author affiliations

${ }^{1}$ Institute of Health Sciences, Collegium Medicum, Jan Kochanowski University, Kielce, Poland

${ }^{2}$ Department of Rehabilitation, Holycross Cancer Centre, Kielce, Poland

${ }^{3}$ Department of Epidemiology and Cancer Control, Holycross Cancer Centre, Kielce, Poland

${ }^{4}$ Clinical Oncology Clinic, Holycross Cancer Centre, Kielce, Poland

${ }^{5}$ Research and Education Department, Holycross Cancer Centre, Kielce, Poland

${ }^{6}$ Radiotherapy Clinic, Holycross Cancer Centre, Kielce, Poland

Acknowledgements The Authors are most grateful to all participants for their committed involvement in the study protocol, despite numerous inconveniences this may have caused them.

Contributors MB: conceptualisation, software, supervision, resources, writingreview and editing. PM: conceptualisation, formal analysis, investigation, methodology, project administration, resources, supervision, writing-review and editing. SG: formal analysis, funding acquisition, investigation, supervision, validation. MT-D: data curation, formal analysis, project administration, software, validation. HK: data curation, project administration, resources. PK: funding acquisition, software, supervision, visualisation. MZ: conceptualisation, formal analysis, investigation, methodology, validation, writing-original draft, writingreview and editing. All Authors gave final approval of the version to be published, and agreed to be held accountable for all aspects of the work.

Funding Implementation of a research project (Ref. No PNRF-228-Al-1/07: PONS - Polish-Norwegian Study) 'Establishment of the infrastructure to facilitate studies on the health status of Poland's population': PNRF-228-Al-1/07, financed out of the Polish-Norwegian Foundation Research Fund. The project is supported under the programme established by the Minister of Science and Higher Education, named 'Regional Initiative of Excellence', spanning the period 2019-2022; Project No 024/ RID/2018/19, amount of financing: PLN 11999000.00

Competing interests None declared.

Patient consent for publication Not required.

Ethics approval The present study was duly approved by a local Ethics Review Committee, Faculty of Health Sciences (Approval Ref. No. 25/2015), The Jan Kochanowski University (JKU) in Kielce, Poland.

Provenance and peer review Not commissioned; externally peer reviewed.

Data availability statement Data are available on reasonable request. Data availability statement even though the source datasets analysed in this article are not publicly available, they may be made available to the researchers by the corresponding author on reasonable request, subject to the applicable legal restrictions in place.

Supplemental material This content has been supplied by the author(s). It has not been vetted by BMJ Publishing Group Limited (BMJ) and may not have been peer-reviewed. Any opinions or recommendations discussed are solely those of the author(s) and are not endorsed by BMJ. BMJ disclaims all liability and responsibility arising from any reliance placed on the content. Where the content includes any translated material, BMJ does not warrant the accuracy and reliability of the translations (including but not limited to local regulations, clinical guidelines, terminology, drug names and drug dosages), and is not responsible for any error and/or omissions arising from translation and adaptation or otherwise.

Open access This is an open access article distributed in accordance with the Creative Commons Attribution Non Commercial (CC BY-NC 4.0) license, which permits others to distribute, remix, adapt, build upon this work non-commercially, and license their derivative works on different terms, provided the original work is properly cited, appropriate credit is given, any changes made indicated, and the use is non-commercial. See: http://creativecommons.org/licenses/by-nc/4.0/.

ORCID iD

Marek Zak http://orcid.org/0000-0003-0881-9232

\section{REFERENCES}

1 Liao C, Gao W, Cao W, et al. Association of educational level and marital status with obesity: a study of Chinese twins. Twin Res Hum Genet 2018;21:126-35.

2 Xiao $\mathrm{Y}$, Zhao N, Wang $\mathrm{H}$, et al. Association between socioeconomic status and obesity in a Chinese adult population. BMC Public Health 2013;13:355.
3 Bullock VE, Griffiths P, Sherar LB, et al. Sitting time and obesity in a sample of adults from Europe and the USA. Ann Hum Biol 2017;44:230-6.

4 de Leiva A. What are the benefits of moderate weight loss? Exp Clin Endocrinol Diabetes 1998;106 Suppl 2:10-13.

5 Assari S, Lankarani MM. The association between obesity and weight loss intention weaker among blacks and men than whites and women. J Racial Ethn Health Disparities 2015;2:414-20.

6 Macek P, Terek-Derszniak M, Zak M, et al. WHO recommendations on physical activity versus compliance rate within a specific urban population as assessed through IPAQ survey: a cross-sectional cohort study. BMJ Open 2019;9:e028334.

7 Clifton PM, Keogh JB. Effects of different weight loss approaches on CVD risk. Curr Atheroscler Rep 2018;20:27.

8 Suliga E. Abdominal obesity - methods of assesment, causes, health implications, 2012. Available: https://studiamedyczne.ujk. edu.pl/index.php?option=com_content\&view=article\&id=435: otyo-brzuszna-metody-oceny-przyczyny-wystpowania-implikacjezdrowotne\&catid=81:tom- $x$ xvii\&Itemid=102 [Accessed 08 Jan 2021].

9 Macek P, Biskup M, Terek-Derszniak M, et al. Optimal body fat percentage cut-off values in predicting the obesity-related cardiovascular risk factors: a cross-sectional cohort study. Diabetes Metab Syndr Obes 2020;13:1587-97.

10 Yatsuya H, Li Y, Hilawe EH, et al. Global trend in overweight and obesity and its association with cardiovascular disease incidence. Circ J 2014;78:2807-18.

11 Delaet D, Schauer D. Obesity in adults. BMJ Clin Evid 2011;2011. [Epub ahead of print: 17 Mar 2011].

12 Biskup M, Macek P, Król H, et al. The role of the rs 1421085 polymorphism in the pathogenesis of obesity. Sm 2020;36:110-5

13 Bray GA, Frühbeck G, Ryan DH, et al. Management of obesity. The Lancet 2016;387:1947-56.

14 Macek P, Zak M, Terek-Derszniak M, et al. Age-Dependent disparities in the prevalence of single and clustering cardiovascular risk factors: a cross-sectional cohort study in middle-aged and older adults. Clin Interv Aging 2020;15:161-9.

15 Macek P, Biskup M, Ciepiela P, et al. Changes in survival of colorectal cancer patients in Świętokrzyskie province (Southern Poland) from the second half of the 1990s to the early 21 st century - a populationbased study. Ann Agric Environ Med 2020;27:301-5.

16 Macek P, Terek-Derszniak M, Biskup M, et al. A two-year followup cohort study-improved clinical control over CVD risk factors through weight loss in middle-aged and older adults. J Clin Med 2020;9:2904.

17 Newton S, Braithwaite D, Akinyemiju TF. Socio-Economic status over the life course and obesity: systematic review and meta-analysis. PLoS One 2017;12:e0177151.

18 Aitsi-Selmi A, Batty GD, Barbieri MA, et al. Childhood socioeconomic position, adult socioeconomic position and social mobility in relation to markers of adiposity in early adulthood: evidence of differential effects by gender in the 1978/79 Ribeirao Preto cohort study. Int $J$ Obes 2013:37:439-47.

19 Bhurosy T, Jeewon R. Pitfalls of using body mass index (BMI) in assessment of obesity risk. Curr Res Nutr Food Sci 2013;1:71-6 https://www.foodandnutritionjournal.org/volume1number1/pitfalls-ofusing-body-mass-index-bmi-in-assessment-of-obesity-risk/

20 Cohen AK, Rai M, Rehkopf DH, et al. Educational attainment and obesity: a systematic review. Obes Rev 2013;14:989-1005.

21 León-Muñoz LM, Gutiérrez-Fisac JL, Guallar-Castillón P, et al. Contribution of lifestyle factors to educational differences in abdominal obesity among the adult population. Clin Nutr 2014:33:836-43.

22 Boissonnet C, Schargrodsky H, Pellegrini F, et al. Educational inequalities in obesity, abdominal obesity, and metabolic syndrome in seven Latin American cities: the CARMELA study. Eur J Cardiovasc Prev Rehabil 2011;18:550-6.

23 Coll JL, Bibiloni MdelM, Salas R, et al. Prevalence and related risk factors of overweight and obesity among the adult population in the Balearic Islands, a Mediterranean region. Obes Facts 2015;8:220-33.

24 Gutiérrez-Fisac JL, Guallar-Castillón P, León-Muñoz LM. Prevalence of general and abdominal obesity in the adult population of Spain, 2008-2010: the ENRICA study. Obes Rev Off J Int Assoc Study Obes 2012;13:388-92.

25 Zhang H, Xu H, Song F, et al. Relation of socioeconomic status to overweight and obesity: a large population-based study of Chinese adults. Ann Hum Biol 2017:44:495-501.

26 López-Sobaler AM, Rodríguez-Rodríguez E, Aranceta-Bartrina J, et al. General and abdominal obesity is related to physical activity, smoking and sleeping behaviours and mediated by the educational level: findings from the ANIBES study in Spain. PLoS One 2016;11:e0169027. 
27 Sen J, Mondal N, Dutta S. Factors affecting overweight and obesity among urban adults: a cross-sectional study 2013.

28 Dinsa GD, Goryakin Y, Fumagalli E, et al. Obesity and socioeconomic status in developing countries: a systematic review. Obes Rev 2012;13:1067-79.

29 Vieira LS, Bierhals IO, Vaz JDS, et al. Socioeconomic status throughout life and body mass index: a systematic review and metaanalysis. Cad Saude Publica 2019;35:e00125518.

30 Han E, Norton EC, Powell LM. Direct and indirect effects of body weight on adult wages. Econ Hum Biol 2011;9:381-92.

31 Flint SW, Čadek M, Codreanu SC, et al. Obesity discrimination in the recruitment process: "you're not hired!". Front Psychol 2016;7:647.

32 Mensinger JL, Tylka TL, Calamari ME. Mechanisms underlying weight status and healthcare avoidance in women: a study of weight stigma, body-related shame and guilt, and healthcare stress. Body Image 2018;25:139-47.

33 Puhl R, Suh Y. Health consequences of weight stigma: implications for obesity prevention and treatment. Curr Obes Rep 2015;4:182-90.

$34 \mathrm{Kim}$ TJ, von dem Knesebeck $\mathrm{O}$. Income and obesity: what is the direction of the relationship? A systematic review and meta-analysis. BMJ Open 2018;8:e019862.

35 Kim J, Sharma SV, Park SK. Association between socioeconomic status and obesity in adults: evidence from the 2001 to 2009 Korea
National health and nutrition examination survey. J Prev Med Public Health 2014:47:94-103.

36 Park S, Pan L, Lankford T. Relationship between employment characteristics and obesity among employed U.S. adults. Am J Health Promot 2014;28:389-96.

37 Poterico JA, Stanojevic S, Ruiz-Grosso P, et al. The association between socioeconomic status and obesity in Peruvian women. Obesity 2012;20:2283-9.

38 Jack D, Neckerman K, Schwartz-Soicher O, et al. Socio-Economic status, neighbourhood food environments and consumption of fruits and vegetables in New York City. Public Health Nutr 2013;16:1197-205.

39 Ball K, Lamb KE, Costa C, et al. Neighbourhood socioeconomic disadvantage and fruit and vegetable consumption: a seven countries comparison. Int J Behav Nutr Phys Act 2015;12:68.

40 Soriguer F, Rojo-Martínez G, Esteva de Antonio I, et al. Prevalence of obesity in south-east Spain and its relation with social and health factors. Eur J Epidemiol 2004;19:33-40.

41 Kilicarslan A, Isildak M, Guven GS, et al. Demographic, socioeconomic and educational aspects of obesity in an adult population. J Natl Med Assoc 2006;98:1313-7.

42 Tzotzas T, Vlahavas G, Papadopoulou SK, et al. Marital status and educational level associated to obesity in Greek adults: data from the National epidemiological survey. BMC Public Health 2010;10:732. 